\title{
The decision making process regarding the withdrawal or withholding of potential life-saving treatments in a children's hospital
}

Karen Street, Richard Ashcroft, John Henderson and Alastair V Campbell South West Deanery, Paediatrics and University of Bristol

\begin{abstract}
Objectives-To investigate the factors considered by staff, and the practicalities involved in the decision making process regarding the withdrawal or withholding of potential life-sustaining treatment in a children's hospital. To compare our current practice with that recommended by the Royal College of Paediatrics and Child Health (RCPCH) guidelines, published in 1997.

Design - A prospective, observational study using self-reported questionnaires.

Setting-Tertiary paediatric hospital.

Patients and participants-Consecutive patients identified during a six-month period, about whom a formal discussion took place between medical staff, nursing staff and family regarding the withholding or withdrawal of potentially life-sustaining treatments. The primary physician and primary nurse involved in the discussion were identified.

Method-Two questionnaires completed independently by the primary physician and nurse.

Results-Twenty-two patients were identified (median age 1 year; range 1 day-34 years). In 20 cases treatment was withdrawn or withheld, in two cases treatment was continued. Nursing staff considered family wishes and family perceptions of patient suffering as significantly more important factors in decision making than medical staff, who considered prognostic factors as most important. In only two cases were the patient's expressed wishes apparently available. In most cases staff considered the patient's best interests were served and the process would not be enhanced by the involvement of an independent ethics committee. The exceptions were those cases in which treatment was continued following disagreement between parties.

Conclusions-Our current practice is consistent with that recommended by the $\mathrm{RCPCH}$. The contribution of the patient, provision of staff counselling and general practitioner (GP) involvement were identified as areas for improvement.

(Fournal of Medical Ethics 2000;26:346-352)
\end{abstract}

Keywords: Withdrawal; limitation; life-sustaining; therapy; treatment

\section{The purpose of medicine}

"To do away with the sufferings of the sick, to lessen the violence of disease and to refuse to treat those who are overmastered by their disease."

Hippocrates $^{1}$

\section{Introduction}

The ability to treat disease and to sustain life by artificial means is continually advancing. At the same time there is increasing recognition of the need to acknowledge when limits have been reached in any individual patient and continued treatment is no longer in that patient's best interests. This requires both medical and ethical considerations to be taken into account.

\section{Adult patients}

Twenty-five years ago the majority of patients who died in hospital had failed cardiopulmonary resuscitation. In more recent years, studies have shown that $35-85 \%$ of deaths in intensive care units (ICU) now follow a decision to withdraw or withhold life support. $^{2-8}$ In these situations most of the patients will be acutely incapacitated and therefore few contribute directly to the decision making process. ${ }^{46}$ In some cases patients have written "advance directives" and there is a continuing debate about the validity of these.

Patient autonomy may be improved by the practice of making a "do not resuscitate order" (DNR) on terminally ill/debilitated patients prior to an acute crisis. Such decisions may be ultimately responsible for up to twice as many deaths on the wards compared to those on the ICU, and as many as $20 \%$ of hospitalised patients are considered for such an order. ${ }^{910}$ However, involvement of the ward patient in these decisions is variable and only marginally greater than the involvement of ICU patients ${ }^{46910}$

Decisions often have to be taken by the doctor and a "surrogate" which will usually be a member/s of the patient's family. Many adults are likely to have expressed opinions regarding life-sustaining 
treatments and quality of life issues in conversation with loved ones. A nursing study found reasonable congruence between decisions made by patients and their surrogates. ${ }^{11}$

A number of medical studies have attempted to identify the factors considered by physicians in such decisions. They have shown that doctors most frequently cite futility of treatment, poor prognosis and imminent death as the most important factors in their decision making. ${ }^{412}$ In many cases judgments regarding quality of life are also considered very important. ${ }^{812}{ }^{13}$ Doctors are not always confident of their decisions in these difficult situations, and do not always agree with each other. ${ }^{14}$ An American study has shown that by using a proactive ethical consultation team, communication can be improved and decisions reached more quickly thus saving hospital time and money without changing outcome. ${ }^{15}$ One can argue, however, that speed is not a major factor and that many families need time to accept such difficult decisions.

\section{Paediatric patients}

The principle of autonomy poses the greatest difficulty when making decisions concerning lifesustaining treatment in a child. Until recently most of the research into withdrawing or withholding treatment in paediatric practice addressed the neonatal age group (0-28 days).

\section{Neonates}

The British Paediatric Association (BPA) has shown that withdrawal of treatment accounts for up to $30 \%$ of neonatal intensive care deaths in the UK. ${ }^{16}$ In these cases the patient, although a potentially autonomous individual, has had no prior quality of life on which to base a judgment. These patients have no ability to contribute to decision making and they have no personality with which the parent has been able to interact on an intellectual level. In the majority of cases decisions are made following discussion between parents and doctors. The factors most frequently cited by physicians as the most important in decision making are once again poor prognosis and imminent death. However, as with adult practice, many consider some form of "quality of life" judgment as important in over half of cases and they may be the sole decision making factor in up to $25 \%$ of cases. Doctors also rate highly the opinions of parents in making such decisions. ${ }^{17-20}$

\section{Children}

Mortality rates in children are much lower than in adult and neonatal populations. Therefore, in absolute numbers, fewer children die following a decision to withdraw or withhold treatment. It is, however, the commonest mode of death in the paediatric population. Most of these deaths occur in paediatric intensive care units (PICU), accounting for up to $65 \%$ of total deaths in this setting. The children concerned tend to be of the younger age group (less than one year) and up to $50 \%$ have underlying chronic disease/abnormality. ${ }^{21-26}$ This is consistent with childhood mortality trends in general. The use of a DNR order on paediatric patients outside the PICU, with the possible exception of oncology, is very uncommon. Such patients account for only a very small number of paediatric hospital deaths $(<5 \%)$ and tend to be in the older paediatric population. ${ }^{27}$

The few studies that have examined decision making factors in this age group are predominantly retrospective. Once again they have shown that poor prognosis and imminent death are the most important factors, but physicians are more reluctant to use quality of life judgments in decision making regarding children, compared to neonates and adults. ${ }^{2325} 28 \mathrm{~A}$ Canadian study using hypothetical paediatric cases found considerable variation in the decisions made by health workers. ${ }^{28}$

The Royal College of Paediatrics and Child Health (RCPCH) recently concluded a two-year period of consultation with professional and patients' interest groups with the publication of the document, Withholding or Withdrawing Lifesustaining Treatment in Children: A Framework for Practice. ${ }^{29}$ The aim of our study was prospectively to investigate the factors considered by the individuals involved in the decision making process regarding potential life-sustaining treatments in a tertiary children's hospital. We also identify the practicalities involved and compare our current practice to the recommendations in the RCPCH guidelines.

\section{Methods}

The study took place over a six-month period from January to July 1998 at the Bristol Royal Hospital for Sick Children (BRHSC). The hospital has an active bone-marrow transplantation programme which includes some adult patients. We did not exclude subjects on the basis of age as our intention was to examine institutional practice.

As this was regarded as an "audit study" of current practice within our institution, approval of the institutional Research Ethics Committee (REC) was not required.

The inclusion criteria for the study were that the patient was cared for in BRHSC and that a formal discussion took place between medical staff, nursing staff and family, including the patient where applicable, regarding the possible withholding or withdrawal of potentially life-sustaining treatment. All consultant staff, hospital and ward managers were informed by letter or in person of the nature of the study. No reference was made in this information to the RCPCH guidelines. Nursing and medical staff informed us whenever a qualifying discussion took place and, within 48 hours of notification, the first of two questionnaires was sent to the primary physician and independently to the primary nurse involved in the discussion. Patient and staff identifiers were coded by the investigators to ensure anonymity. The only reference to patient or staff names was on a detachable front sheet on the questionnaire and staff were 
348 The decision making process regarding the withdrawal or withholding of potential life-saving treatments in a children's hospital

Table 1 Factors involved in decision making

1. Poor prognosis for acute survival

2. Poor prognosis for long term survival

3. Poor quality of life should they survive the acute illness

4. Family expressed wishes

5. Patients expressed wishes during the acute illness

6. Patients previously expressed wishes

7. Dissent between parties

. Physical health prior to admission

9. Intolerable suffering of the patient long term

10. Family structure/support/resources

11. Family perception of unbearable acute suffering

12. Family perception of poor quality of life long term

13. Intolerable suffering during the acute illness

14. Hospital resources

instructed to remove and destroy this prior to returning the questionnaire.

The first questionnaire contained questions relating to the decision making process. We asked the subject who, in their opinion, initiated the formal discussion about withdrawing or withholding treatment. We then asked the subject to indicate the importance of the contribution of i) defined individuals and ii) potentially contributory factors, to the final decision. These factors were chosen to represent a number of domains, including medica diagnoses and prognoses, quality of life, pain and suffering, family resources, hospital resources, and potential conflicts between any of the parties involved (table 1). The importance of each factor was scaled by the respondent according to a six-point numerical scale $(0=$ not relevant, $1=$ relevant but not important, $2=$ minimally important, $3=$ moderately important, $4=$ very important and $5=$ extremely important). Further interpretation of the wording of the factors and the scale of importance was left to the individual respondent. In particular we did not define any formal scale for quality of life judgment.

Within 48 hours of return of the completed first questionnaire, a second questionnaire was sent. This questionnaire addressed the recommendations in the RCPCH guidelines including whether, in the opinion of the staff member, the patient's opinion was sought and respected and whether the patient, the family and the staff were counselled following the decision. The outcome of the discussion was reported and, where relevant, what palliative steps were taken. The respondent was then asked to judge who, in their opinion, made the final decision and whether he or she believed that the best interests of the patient were served. Finally, subjects were asked to categorise the individual circumstances according to the five published criteria proposed by the RCPCH for withholding or withdrawing treatment. These were tabulated in the questionnaire using identical words to those published in RCPCH guidelines (see Appendix at the end of the paper).

\section{Results}

During the six-month study period we identified 22 patients who met our study criteria. During the same period there were 28 deaths in the hospital of whom 17 were children in our study who died after a decision to withhold or withdraw treatment of the remaining five patients in our study, two died in other hospitals, one died at home, and two are still living. Forty-one initial questionnaires and $40 \mathrm{sec}-$ ond questionnaires were returned. Response rates were $86 \%$ for medical staff and $92 \%$ for nurses. We had complete questionnaire data (medical and nursing staff returned both questionnaires) for 16 patients. In three cases we had data from medical staff only and in three cases from nurses only. In two cases we had data from nurses in addition to the nominated primary nurse. The median time to return the questionnaires was 17 days (nurses 14 days; doctors 20 days).

Patients ranged in age from one day to 34 years (median one year). The decision was made to withdraw or withhold treatment following discussion in 20 of the 22 cases; all of these patients subsequently died. In 13 patients the decision was to withdraw assisted ventilation, in six patients to withhold assisted ventilation in the event of respiratory failure and to withhold cardiopulmonary resuscitation (CPR) in the event of a cardiac arrest. In the final patient the decision was to continue ventilation but withold CPR in the event of a cardiac arrest. In all 20 patients palliation with opiates and/or nursing methods was used.

The formal discussion regarding withholding or withdrawing treatment was judged to be initiated by the primary physician or an associated specialist physician in 15 cases and by the parents in four cases. In three cases there was disagreement between medical and nursing staff-in two cases each party believed he/she was the initiator and in one case the physician felt the parents had raised the issue and the nurse felt the physician had done so.

The frequency of contributions of relevant parties and their relative importance to the discussion as judged subjectively on a scale of $0-5$ by the questionnaire respondents is shown in figure 1 . Ranks of 0 or 1 were excluded as being either irrelevant or unimportant to the discussion. Nurses

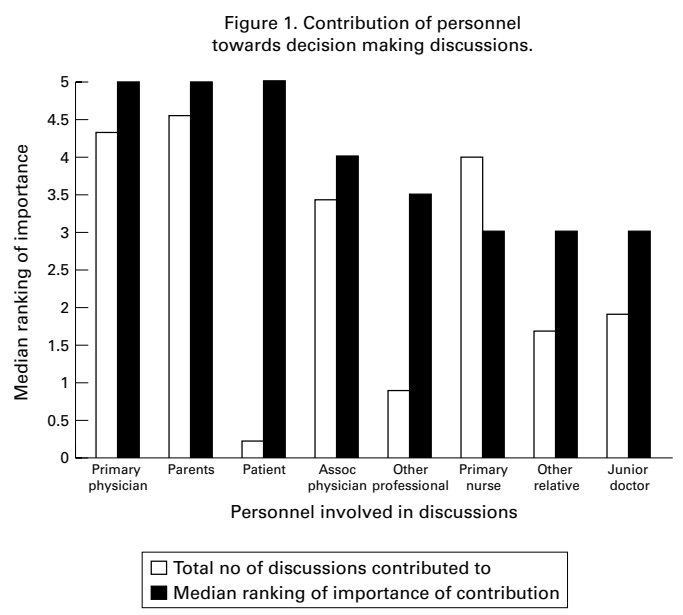


Figure 2. Consideration of factors in decision making discussions.

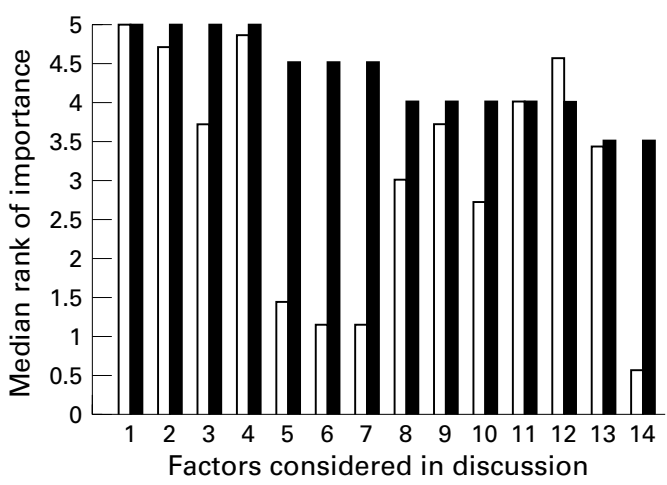

Total no of discussions in which considered

Median ranking of importance towards decision

gave a greater weighting of importance than doctors to all parties' contributions except their own. Figure 2 demonstrates the contributions of potential factors to the outcome decision with the same exclusion of ranks 0 or 1 . Comparison of the responses by doctors and nurses showed that nurses tended to give higher weighting than doctors to the majority of contributory factors. These differences were statistically significant (Wilcoxon matched-pairs signed rank test) for three factors; factor 4-family expressed wishes $(p=0.005)$, factor 8-physical health prior to admission $(p=0.046)$, and factor 11 -family perception of unbearable suffering $(p=0.007)$.

Doctors' awareness of the RCPCH guidelines was high (17/18 medical respondents knew of their existence) but only 12 had read them and four found them useful. Eight of 22 nursing respondents were aware of the guidelines but only two had read them, of whom one found them useful in that particular case.

In only one case (a 20-year-old) was the patient involved directly in the discussions and therefore judged to have been listened to, informed and his/her opinion respected. In a further case (a 34-year-old) the patient was too ill at the time of discussions to take part but previously expressed wishes were respected. In all other cases the patient was judged to be too young or too ill to be involved and no child was reported to have expressed prior directives or wishes.

Counselling of the family occurred in 18 cases after the decision. Counselling of staff clearly occurred in two cases and in a further six cases it was judged by the medical staff to have occurred but the nurses did not agree.

In all but two cases, in the opinion of the medical and nursing staff involved, the patient's best interests had been served. In the two cases where this was not believed to be the case, treatment was not withdrawn. Only one doctor and one nurse would have preferred the eventual decision to have been made by an independent ethics committee.

In the opinion of the respondents the final decision regarding withholding or withdrawal of treatment was judged to be made by parents alone in four cases (in two of these some degree of treatment was continued) and by the consultant alone in two cases. In the remainder the opinion was that the decision was reached jointly by medical staff and parents, although in six cases the medical staff believed they had made the decision whereas the nurses believed it to have been made by the parents. In only three cases did the nursing staff include themselves as having made the final decision.

When RCPCH categories were applied, only six patients could be categorised into a single definition (four "No Chance", one "Brain Dead", 1 "No Purpose"). In all other 16 cases the patient fitted more than one category and there were no instances in which the categories did not apply.

\section{Discussion}

Our study is a prospective, observational study of current practice and individual opinions in one institution. The conclusions that can be drawn relate only to the opinions of medical and nursing staff. An important weakness of our study is the lack of data collection from the parents and families. This would obviously require very sensitive handling. Our intention on embarking on this study was to interpret the usefulness of these initial results from medical and nursing personnel before designing a study to compare families' experiences with the interpretation of events by clinical staff.

There are a number of methodological constraints on the interpretation of our results. We used a closed questionnaire format which may not have allowed for all possible responses. However, we did give respondents the option to add comments at the end of each section of the questionnaire, which many did. These responses did not highlight a consistent failure of the questionnaire to address specific points.

We also relied on individual interpretation of the wording of the factors and the numerical scale of importance.

One of our aims was to compare our current practice to that recommended by the RCPCH guidelines which for the purposes of this study were accepted at face value, as we were doing a "pragmatic" study which relied on individuals' interpretations of the "rules". Critical discussion of their contents is outside the scope of our paper. To avoid staff attempting to modify their responses to expectations based on published guidelines there was no mention of the guidelines in the first questionnaire, hence our study design using two consecutive sets of questions. For the same reason we did not mention the RCPCH guidelines in our initial warning to staff that the study was being performed, indeed we did not discuss any details of the study at this stage. Of course, a number of staff were involved in the care of more than one patient who met the study criteria and general knowledge of the 
350 The decision making process regarding the withdrawal or withholding of potential life-saving treatments in a children's hospital

study among staff may have led to increasing recognition of the emphasis on the guidelines. However, inspection of the responses of staff completing questionnaires on more than one patient did not indicate systematic differences in subsequent responses to the first set of questionnaires.

In the original design of our study we considered alternative methods of data collection. Personal interview of the subjects may have allowed more open questioning, however we felt that it was more likely to make it difficult for respondents to be honest in answering ethically challenging questions than an anonymous questionnaire. Records of discussion in medical notes do not contain sufficien detail to enable collection of the data we required. The presence of an independent observer during the discussion may have altered the content of that discussion and influenced our observations. As we were interested in individuals, current attitudes and practices within our institution we favoured the questionnaire approach for this preliminary study. However, we recognise the strengths of persona interviews in obtaining information about how and why decisions were made and plan to use these methods in subsequent work.

Our case identification methods may have led to important omissions in the study population. We identified all hospital deaths during the study period and did not identify any potential cases where a patient died and met our study criteria. It is possible that we were more likely to be informed if a decision was for withdrawal of treatment than for continuation. We did identify one group of patients who did not meet our defined criteria. These were long term oncology patients in whom decisions were made and implemented or revoked after a series of discussions, often over protracted periods of time. It was impossible therefore to identify a single discussion at which a particular decision was reached. Four of the hospital deaths during our study applied to this group. Our results are likely to be more relevant to acute conditions where such considerations have not been previously discussed. This may explain why patients' previously expressed wishes were not seen as important contributors to final decisions.

Despite these limitations we feel our study has raised important issues for this poorly researched topic, which may be useful to ourselves and others in further research and improving practice.

\section{Children's rights in decision making}

A child's decision making capacity will be dependent on his or her cognitive ability and previous experience rather than chronological age. Children with chronic illness or disability are likely to have a greater understanding of treatment issues than their peers.

Of the patients in our study only two older patients (both $>16$ years) were considered able to express their opinions. We could identify two patients with chronic illnesses (age nine and 16 years) who might reasonably have been expected to have sufficient cognitive ability and understanding to make informed choices about their treatment. In both cases no prior wishes were apparently expressed before a crisis emerged which rendered them too ill to be consulted further. It is possible that data from parents would dispute this, although their presence at the discussions should have enabled expression of any known wishes.

The landmark Gillick case in 1985 ruled that children who are considered competent to make their own decisions can consent to medical treatment. This recognition of the right of a child to take part in decision making concerning him/ herself was formalised in two important documents. The first, the United Nations Convention on the Rights of the Child, 1989, introduces the concept that the primary consideration in any action involving children should be their "best interests", and that they have the right to seek and express opinions. The views of children should be given "due weight in accordance with their age and maturity". ${ }^{30}$ These principles were incorporated into an overall statutory framework for the provision of childrens' welfare services in this country, The Children Act, $1989 .{ }^{31}$ The basic principles behind this act are that a child's welfare is paramount and that "particular regard should be paid to a child's ascertainable wishes and feelings".

Part of the management of children with chronic, potentially life-threatening illness should be actively to seek their opinions on such matters wherever possible using age-appropriate means, and this should be done by people practised in communicating with children.

\section{Parental rights in decision making}

In situations where children are unable to contribute, it is accepted that parents have authority to make decisions on their behalf. It is assumed that parents will have a profound love and commitment towards their child's welfare. They also share religious, cultural and family beliefs with the child and it is assumed therefore that they are best placed to make surrogate decisions on behalf of their child. It is understandable that in many cases they may be too emotionally involved to make an objective decision that is in their child's best interests. The Children Act established the concept of parental responsibility which enables an individual to make decisions on behalf of his or her child, in the child's best interests. The responsible parent is both mother and father if they are married. If not, there has to be either written agreement from the mother or a court ruling that gives the father responsibility. In certain circumstances the court can take on parental responsibility or it can be sought by external persons. Following the Gillick ruling in 1985, further rulings by the Court of Appeal in 1991 and 1992 made it clear that a parent can overrule a child's decision even when the child is judged competent.

Our results have clearly demonstrated that parents were involved in all decisions and their expressed wishes were considered by staff to be very important. The presence of other relatives in 
discussions was commonplace and their input was also highly rated.

\section{Medical and nursing staff}

Our results suggest that nurses were not always involved in discussions. This is likely to have arisen as a result of our use of the term "primary nurse" in instructions to respondents. The named primary nurse may not have been present during discussions but would usually be substituted by a member of the primary nursing team who cared for the patient and knew the family.

There was a significant difference in the weight given to parents' wishes and their beliefs regarding suffering and future quality of life by nurses compared to doctors. A review in the nursing literature concerning the subject of ethical decision making proposes that the responsibilities of a nurse are the provision of advocacy for the child and for the parents. ${ }^{32}$ Interestingly nurses did not rate their own contributions to be highly important in the decision making process and they rarely included themselves in having made the final decision. One might suggest that it is easier to play the role of advocate if you do not see yourself as a "final decision maker". The nursing input was, however, highly valued by doctors, who played a much greater role in the "final" decision making.

Doctors' duty of care is to their patient. Decisions must be made that are in the best interests of patients, according to knowledge of their medical condition at the time. There is no obligation to treat where it is believed that treatment is futile, indeed to do so would be considered an assault on the patient. Our results support the contention that the most important factors used in decision making are prognostic factors related to the disease process. Personal beliefs regarding suffering and quality of life were considered in approximately two-thirds of cases, however, they were not given the same weight of importance. A critical discussion regarding the use of "quality of life" judgments, particularly in children, is again outside the scope of this paper.

Junior doctors were involved in less than half of the discussions, which we believe represents a significant weakness in their training.

The ideal situation is to reach a decision with the agreement of all concerned but without letting parents feel the burden of responsibility. Our results would suggest that, in the opinion of the medical personnel involved, this was achieved in the 16 patients where the decision was judged to have been jointly made by medical staff and parents.

In the majority of cases staff felt that the patient's best interests were served by discussion between all parties and the process would not be enhanced by the presence of an independent ethics review committee. The possible exceptions were those cases where there was disagreement between the families and the professionals. In both these cases parents alone made the decision to continue treatment. In these situations a second opinion should be sought and independent advice from an ethics advisor or advisory committee may contribute to the discussions. However, we have not attempted to examine the value of an independent ethics advisory committee in the context of this study.

\section{Counselling}

One key weakness was identified in our current practice compared to recommendations in the RCPCH guidelines. This was the provision of staff counselling following decisions. It is interesting to note that medical staff felt that appropriate counselling had been given in more cases than were acknowledged by nurses. This may reflect different professional expectations and interpretations of the counselling process, with medical staff viewing this as an informal process whilst nurses expect a more formal arrangement.

The GP was also rarely involved in the decision making process. It is the GP who is likely to have continued involvement with the family over many years. We therefore felt this was a significant weakness.

\section{Conclusion}

Withdrawal or withholding of treatment is a common precedent to death in a tertiary children's hospital and the decision making process involves a wide range of professionals. The general principles incorporated in the RCPCH guidelines are consistent with our current practice and professionals' views of the important issues in this process. The ethical principles by which we practise medicine require careful consideration and application when it comes to life and death decision making in children. We recommend that anyone involved in these decisions be aware of the ethical, legal and practical issues as they relate to children. The RCPCH guidelines should be readily available and familiar to all such professionals.

\section{Appendix}

Five situations in which the witholding or withdrawing of curative medical treatment might be considered appropriate. (RCPCH guidelines)

The brain dead child.

The permanent vegetative state: Those who are reliant on others for all care and do not react or relate with the outside world.

The "No chance" situation: A child who has such severe disease that life-sustaining treatment simply delays death without significant alleviation of suffering.

The "No purpose" situation: A patient who may be able to survive with treatment but in whom the degree of physical or mental impairment will be so great that it is unreasonable to expect them to bear it.

The "Unbearable" situation: Where the child and/or family feel that in the face of progressive and irreversible illness further treatment is more than can be borne.

Karen Street MA (Oxon), MRCP, is Specialist Registrar in Paediatrics, Southwest Deanery. Richard 
352 The decision making process regarding the withdrawal or withholding of potential life-saving treatments in a children's hospital

Ashcroft, MA, PhD, is Lecturer in Medical Ethics, Department of Primary Care and General Practice, Imperial College School of Medicine, St Mary's Hospital, London. Fohn Henderson, MD, FRCP, FRCP (Edin), FRCPCH, is Senior Lecturer in Child Health, Institute of Child Health, University of Bristol. Alastair $V$ Campbell, $M A, B D$, ThD, is Professor of Ethics in Medicine, University of Bristol.

Correspondence to: Dr Karen Street, Knapp Cottage, Knapp Rd East, Thornbury BS35 2HF. Phone: 01454 418877;E-mail: karen_street_khan@yahoo.co.uk

\section{References and notes}

1 Cited in: Jecker NS. Knowing when to stop: the limits of medicine. Hastings Center Report 1991;21:5-8.

cine. Hastings Center Report 1991;21:5-8. terminal illness and brain death. Critical Care Medicine 1978;6: 284-91.

3 Vincent JL, Parquier JN, Preiser JP, et al. Terminal events in the intensive care unit: review of 258 fatal cases in one year. Criti-

4 Smedira NG, Evans BH, Grais LS, et al. Witholding and withdrawal of support from the critically ill. New England fournal of Medicine 1990;322:309-15.

5 Koch KA, Rodeffer HD, Wears RL. Changing patterns of terminal care management in an intensive care unit. Critical Care Medicine 1994;22:233-43.

6 Wood GG, Martin E. Witholding and withdrawing lifesustaining therapy in a Canadian intensive care unit. Canadian fournal of Anaesthesia 1995;42:186-91.

7 Turner JS, Michell WL, Morgan CJ, Benatar SR. Withdrawal of life support. Frequency and practice in a London and a Cape Town intensive care unit. Intensive Care Medicine 1996.22: 1020-5.

8 Keenan SP, Busche KD, Chen LM, McCarthy L, et al. A retrospective review of a large cohort of patients undergoing the spective review of a large cohort of patients undergoing the Care Medicine 1997;25:1324-31.

9 Jonsson PV, McNamee M, Campion EW. The 'Do not resuscitate' order. A profile of its changing use. Archives of Internal Medicine 1988;148:2373-5.

10 Evans AL, Brody BA. The do-not-resuscitate order in teachin hospitals. Fournal of the American Medical Association 1985;253 2236-9.

11 Libbus MK, Russell C. Congruence of decisions between patients and their potential surrogates about life-sustaining therapies. Image - the Fournal of Nursing Scholarship 1995;27: $135-40$.

12 Lee DK, Swinburne AJ, Fedullo AJ, Wahl GW. Withdrawing Care: experience in a medical intensive care unit. Fournal of the American Medical Association 1994;271:1358-61.

13 Faber-Langendoen K, Bartels DM. Process of foregoing life-sustaining treatment in a university hospital Critical Care Medicine 1992;20:570-7.
14 Walter SD, Cook DJ, Guyatt GH, Spanier A, et al. Confidence in life-support decisions in the intensive care unit: a survey of health workers. Critical Care Medicine 1998;26:44-9.

15 Dowdy MD, Robertson C, Bander JA. A study of proactive ethics consultation for critically and terminally ill patients with extended lengths of stay. Critical Care Medicine 1998;26:252-9.

16 House of Lords Select Committee on Medical Ethics. Report of the House of Lords Select Committee on Medical Ethics [vol 1].1994: 47.

17 Cook LA, Watchko JF. Decision making for the critically ill neonate near the end of life. Fournal of Perinatology 1996;16: 133-6.

18 van der Heide A, van der Maas PJ, van der Wal G, Kollee LA, de Leeuw R, Holl RA. The role of parents in end of life decisions in neonatology: physicians' views and practices. Pediatrics 1998;101:413-18.

19 Wall SN, Partridge JC. Death in the intensive care nursery: physician practice of withdrawing and witholding life support. Pediatrics. 1997;99:64-70

20 Duff RS, Campbell AGM. Moral and ethical dilemmas in the special care nursery. New England fournal of Medicine 1973;289:890-4.

21 Martinot A, Lejeune C, Hue V, Fourier C, Beyuert C, Diependaele JF, et al. Modality and causes of 259 deaths in a paediatric intensive care unit. Archives de Pediatrie 1995;2:735-41.

22 Balfour-Lynn IM, Tasker RC. At the coalface - medical ethics in practice: futility and death in paediatric medical intensive care. Fournal of Medical Ethics 1996;22:279-81.

23 Levetown M, Pollack MM, Murray M, Cuerdon TT, Ruttimann UE, Glover JJ. Limitations and withdrawal of medical intervention in paediatric critical care. Fournal of the American Medical Association 1994;272:1271-5.

24 Vernon DD, Dean JM, Timmons OD, Banner W jr, Allen-Webb EM. Modes of death in the pediatric intensive care unit: withdrawal and limitation of supportive care. Critical Care Medicine 1993;21:1798-802.

25 Mink RB, Pollack MM. Resuscitation and withdrawal of therapy in pediatric intensive care. Pediatrics 1992;89:961-3.

26 Ryan CA, Byrne P, Kuhn S, Tybkhan J. No resuscitation and withdrawal of therapy in a neonatal and a pediatric intensive care unit in Canada. Fournal of Pediatrics 1993;124:995-6.

27 Lantos JD, Berger AC, Zucker AR. Do not resuscitate orders in a childrens hospital. Critical Care Medicine 1993;21:52-5.

28 Randolph AG, Zollo MB, Wigton RS, Yeh TS. Factors explaining variability among caregivers in the intent to restrict life-support interventions in a pediatric intensive care unit. Critical Care Medicine 1997;25:435-9.

29 Royal College of Paediatrics and Child Health. Witholding or withdrawing life saving treatment in children: a framework for practice. London: RCPCH, 1997.

30 United Nations Centre for Human Rights and Unicef. The United Nations Convention on the Rights of the Child. Geneva: UN and UNICEF, 1989.

31 House of Commons. The Children Act. London: HMSO, 1989: Cmnd 41.

32 Bracegirdle KE. A time to die: withdrawal of paediatric intensive care. British fournal of Nursing. 1994;3:513-17. 